\title{
URBANIDADE E CRISE
}

\author{
Leandro Medrano
}

No decorrer do século 20, a questão da habitação fundamentou grande parte dos movimentos disciplinares da Arquitetura, do Urbanismo e do Design, e fez que seus limites fossem ampliados às estratégias econômicas e políticas que determinaram o espaço social da maioria dos países ocidentais. Não foram triviais os problemas engendrados nesse percurso: o setor habitacional, sobretudo o da habitação coletiva, teve de responder à crescente demanda dos grandes centros industrializados, ou em processo de industrialização, por meio da busca de novas formas de expressão técnica, concepção espacial e representatividade - arautos do Movimento Moderno difundido em escala mundial. Dessa história recente, não se esgotaram as explicações dadas aos entraves sociais, técnicos e culturais, que dificultaram a resolução dos conflitos relacionados à necessidade de moradias por meio dos métodos de produção em massa, mesmo quando associados ao desenho moderno e/ou às inovadoras diretrizes de governança. 0 mesmo se pode dizer da crítica à racionalização do espaço da casa, pois a unidade residencial, ao aceitar sua autonomia como núcleo doméstico (formal, legal e social), tratou de endossar a hipótese de uma antiurbanidade generalizada.

Nas últimas décadas do século passado, em paralelo ao avanço das políticas econômicas neoliberais, países que não lograram dos primeiros ciclos da industrialização tiveram, na falta de moradias, um de seus maiores problemas urbanos, principalmente nas grandes cidades. Se assiedlungen ou os grands ensembles_criaram problemas estruturais, por representaram os limites estéticos e técnicos da arquitetura racional - bem como os limites da própria Modernidade -, nos países ditos periféricos os ciclos econômicos e as políticas de Estado não permitiram nem mesmo que os instrumentos da disciplina fossem exercidos, em grande escala, como atenuadores da precária situação das moradias destinadas à população de baixa renda. Ademais, a financeirização do sistema produtivo em geral e do setor habitacional em particular, acelerada a partir dos anos 1980, acentuou a distância entre as necessidades urbanas do habitar e a simples produção de habitação como mercadoria desterritorializada - um ativo precário, como bem demostrou a crise mundial que teve início com o crash de setembro de 2008.

No caso brasileiro, desde as experiências pioneiras dos Institutos de Aposentadoria e Pensão (IAPs), até o Programa Minha Casa Minha Vida (PMCMV),os avanços relacionados à provisão de moradia para os trabalhadores com pouca ou nenhuma renda foram insuficientes para equacionar o déficit habitacional nacional, atualmente estimado em aproximadamente 5 milhões de domicílios. Por um lado, constatam-se as limitações das políticas urbanas vinculadas às demandas estratégicas de setores privados, como o da construção civil, especialmente quando os instrumentos de regulamentação restringem-se ao gerenciamento de uma equação financeira dedicada a articular recursos públicos e privados, com vistas a desempenhos meramente quantitativos. Sem a demarcação clara de um objetivo comum às cidades - como o de uma virtualidade urbana desejada em seu valor de uso -, pouco se poderia esperar de instrumentos econômicos sofisticados e bem intencionados, sobretudo quando consideradas as relações patrimoniais que conformam a estrutura fundiária urbana nacional. Por outro lado, sem a atuação da disciplina em direção à reformulação de suas teorias e métodos, estreitam-se os avanços, no que diz respeito à projetação de espacialidades atentas às especificidades contemporâneas nacionais e locais. Ou seja, sem o projeto de uma articulação mínima entre forma e espaço social,a simulação de 
modernidade que cotejava o desejo real de transformação radical do território e da sociedade foi abalada pela aceitação de modelos genéricos, impostos pelas grandes incorporadoras ligadas ao capital transnacional.

Nessa equação, que agrega os interesses do mercado imobiliário aos dos agentes financeiros, resultaram os novos standards habitacionais dedicados ao mercado popular, bem como os vastos territórios de ocupações informais que definiram o que já foi chamado de um "Planeta Favela", onde grande parte da população vive em estado de precariedade extrema.

A reação a esse processo é evidente. Nos últimos anos, os temas relacionados à Arquitetura, ao Urbanismo e ao Design procuram compreender as possibilidades desses setores, em ambiente de crise econômica mundial-agravada com o esmaecimento de valores pactuados pelas sociedades modernas, como a democracia, a liberdade, os direitos civis e trabalhistas. Os temas espetaculares dos tempos de dinheiro fácil perderam o protagonismo, e a comunidade acadêmica, setores governamentais e colegiados profissionais posicionam-se em direção à conciliação de nossas estruturas sociais com sua maior conquista espacial: a cidade.

Como exemplo, o artigo Nexos entre a redistribuição populacional e a produção imobiliária residencial nos distritos do município de São Paulo, de Anderson Kazuo Nakano, busca compreender as mudanças na estrutura demográfica da região metropolitana de São Paulo, advindas do ciclo de expansão imobiliária que se deu entre 1998 e 2008. O autor analisa dados censitários e do mercado, para identificar as alterações populacionais ocorridas em relação às moradias verticais coletivas, em determinados bairros de São Paulo. O resultado corrobora a hipótese recorrente de que as regiões centrais, portadoras de serviços, empregos, atividades culturais e infraestrutura, adensaram-se nos últimos anos, revertendo um ciclo de esvaziamento que perdurou por décadas seguidas, enquanto as regiões periféricas permaneceram com indicadores populacionais pouco alterados, apesar da verticalização ter se intensificado nessas regiões.

O interesse pela história e pela crítica dedicada à produção habitacional brasileira, em específico à experiência dos IAPs, são destaques nos textos das autoras Nilce Aravecchia Botas e Maria Isabel Imbronito.

0 artigo Trânsito de ideias e conformação de práticas: arquitetura e urbanismo na ação habitacional do IAPI, de Nilce Aravecchia Botas, procura ressaltar as singularidades dos projetos dos IAPIs e das bases formativas que fundamentaram essa experiência de arquitetura moderna pioneira no cenário nacional. Nesse sentido, relata que os técnicos, empenhados na construção de novas hipóteses de ocupação territorial para a moradia dedicada à classe trabalhadora, buscaram tanto alinhar as particularidades desse projeto nacional aos modelos centro-europeus, quanto identificar outras matrizes teóricas úteis às especificidades do Brasil. Sobretudo quando considerados os desafios insertos no desejo de transformação social evocados pela Revolução liderada por Getúlio Vargas - como a possibilidade do surgimento de uma espacialidade operária original, matizada pela intenção de renovação da ordem política e social.

Já a autora Maria Isabel Imbronito, no artigo Conjunto Residencial Santa Cruz: da origem aos dias atuais, procura destacar o processo de desarticulação da estrutura urbana original do IAPB Conjunto Residencial Santa Cruz, projetado em 1947, pelo engenheiro-arquiteto Marcial Fleury de Oliveira. A pesquisa contempla dados históricos e análise do projeto, que sistematizam o processo de formulação dessa experiência singular e suas transformações decorrentes de novas ordens políticas, sociais e fundiárias. Nota-se que o sentido urbano modernizador, almejado por esses e outros 
conjuntos habitacionais da época, não resistiu à realidade espacial adotada pela cidade de São Paulo, a partir da segunda metade do século 20, quando as forças do mercado e o excepcional crescimento de sua população impuseram ordens e demandas até hoje não equacionadas pela disciplina.

ManfredoTafuri é um dos maiores historiadores e críticos da arquitetura do século 20, e sua obra permanece vibrante e atual para a compreensão dos entraves recentes da disciplina. No artigo Dois projetos: os anos de formação de Manfredo Tafuri, Rafael Urano Frajndlich procura problematizar a relação do autor de Teorias e História da Arquitetura (1968) com sua curta e intensa carreira como arquiteto projetista. Os dilemas que envolveram sua opção profissional definitiva parecem ter sido fundamentais para a formação desse intelectual singular, que via na crítica uma possibilidade de transformação e, na história, os valores que dariam complexidade, significado e relevância às contradições que permeiam a arquitetura.

Por outro lado, não é a história, mas sim a técnica, o ponto de partida do ensaio Técnica, arte e questões fundamentais da existência. Considerações sobre o discurso de Paulo Mendes da Rocha, de Maria Isabel Villac. A autora procura revelar, por meio da análise de textos do arquiteto Paulo Mendes da Rocha, os fundamentos de uma racionalidade reflexiva, que faz, do projeto, ensaio e discurso sobre o conhecimento humano e sua dimensão estética. Nesse sentido, a obra do vencedor do Leão de Ouro da Bienal de Veneza de 2016 revelaria, em suas soluções formais, uma consciência social e ética amparada na universalidade de sua racionalidade técnica - que, por sua vez, mostra-se simétrica às suas ambições artísticas.

Conceitos e metodologias relacionados ao processo de projeto na arquitetura e no design são temas do artigo Novos olhares e desafios da complexidade na epistemologia projetual, de Bruno Massa Rocha. 0 autor resgata argumentos de teóricos referenciais, como Donald Schön, Herbert A. Simon,Christopher Alexander, Nicholas Negroponte, entre outros, para refletir sobre o papel da improvisação nas práticas projetuais. Ressalta que o conhecimento, potencializado pelo tensionamento entre o saber teórico e a experiência cotidiana, pode estimular a aproximação entre o abstrato universo do design processe e seus objetivos empíricos.

Por fim, o artigo Patrick Geddes e a escola territorialista italiana: aproximações conceituais e metodológicas. Reflexões a partir da participação de crianças na representação de valores patrimoniais da cidade de Santa Leopoldina, dos autores Bruno Amaral de Andrade e Renata Hermanny de Almeida, relata a atualidade dos conceitos do biólogo e filósofo escocês Patrick Geddes, quanto às questões relacionadas à educação ambiental e urbana. Por meio da uma experiência pedagógica singular, os autores procuram ressaltar a importância da construção de uma consciência crítica em relação à paisagem e ao território, como elementos essenciais ao espaço de vida dos homens.

Os textos selecionados para esta edição da Revista Pós, embora não estejam propriamente interligados por meio de uma estrutura editorial temática, demostram que pensar sobre o que se faz, em tempos de crise, tornou-se uma complexa tarefa para os que se dedicam a produzir conhecimento, nos campos relacionados à Arquitetura, ao Urbanismo e ao Design. Dessa reflexão continuada e sistematizada, deverão surgir alternativas às adversidades urbanas cotidianas dos tempos atuais. Boa leitura.

Leandro Medrano

Editor-Chefe

medrano@usp.br 